\title{
PREVALÊNCIA DE DANO HEPÁTICO EM ALCOOLISTAS EM RECUPERAÇÃO DE UM GRUPO DE ALCOÓLICOS ANÔNIMOS DE PONTA GROSSA - PR
}

\section{PREVALENCE OF HEPATIC DAMAGE IN ALCOHOLISTS IN RECOVERY OF A GROUP OF ALCOHOLICS ANONYMOUS OF PONTA GROSSA - PR}

\section{Fernanda Ferreira de SOUZA'; Daniele Priscila da Silva Fardin de ASSUNÇÃO²; Cristiane Rickli BARBOSA2; Thais Latansio de OLIVEIRA ${ }^{3}$}

\author{
1 - Acadêmica do Curso de Farmácia das Faculdades Ponta Grossa, Ponta Grossa - PR \\ 2 - Doutoranda pelo Programa de Pós Graduação em Ciências Farmacêuticas Universidade Estadual de \\ Ponta Grossa, Ponta Grossa - PR \\ 3 - Doutoranda pelo Programa de Pós Graduação em Ciências Farmacêuticas Universidade Federal do \\ Paraná, Curitiba - PR. \\ Autor para correspondência: tatalatansio@hotmail.com
}

\section{RESUMO:}

O álcool vem sendo apontado como a droga mais consumida no Brasil e o seu consumo em excesso pode gerar danos hepáticos. Pessoas que fazem uso abusivo, depois de alguns anos, podem sofrer com essas complicações. O objetivo deste trabalho foi avaliar os parâmetros bioquímicos das enzimas Transaminase Glutâmica Oxalacética e Pirúvica (TGO e TGP), Gama Glutamil Transferase (GAMA-GT) e o doseamento dos níveis séricos de Albumina de 30 pacientes de um grupo de Alcóolicos Anônimos de Ponta Grossa - Pr. Todos os pacientes avaliados eram do sexo masculino, com uma prevalência maior da faixa etária de 30 - 50 anos. Com relação as enzimas hepáticas deste grupo, o TGO teve uma média entre os pacientes de 28,8 U/L, o TGP teve uma média de 44,6 U/L, já o GAMA-GT teve uma média de 40,8 U/L. Para os níveis séricos de Albumina obteve-se uma média de e 4,9 mg/dL. Assim, os parâmetros bioquímicos em geral estavam dentro dos valores de referência mas as dosagens de TGO e GAMA-GT apresentaram diferença estatística quando comparados ao grupo controle.

Palavras-chave: Álcool; TGO; TGP; GAMA-GT; Albumina.

\begin{abstract}
:
Alcohol has been cited as the drug most consumed in Brazil and its excess consumption can cause liver damage. People who abuse after a few years may suffer from these complications. The objective of this work was to evaluate the biochemical parameters of the enzymes glutamic-oxaloacetic transaminase (GOT) and glutamic-pyruvic transaminase (GPT), Gamma-Glutamyl Transferase (GAMA-GT) and the determination of the serum levels of Albumin of 30 patients from a group of Alcoholics Anonymous of Ponta Grossa Pr. All the patients evaluated were male, with a higher prevalence in the age range of 30 50 years. Regarding the hepatic enzymes of this group, the GOT had an average of $28.8 \mathrm{U}$ / L, the GPT had an average of $44.6 \mathrm{U} / \mathrm{L}$, and the GAMA-GT had an average of $40.8 \mathrm{U} / \mathrm{L}$. For serum levels of albumin an average of $4.9 \mathrm{mg} / \mathrm{dL}$ was obtained. Thus, the biochemical parameters were generally within the reference values but the dosages of GOT and GAMAGT presented statistical difference when compared to the control group.
\end{abstract}

Keywords: Alcohol; GOT; GPT ; GAMA-GT; Albumin. 


\section{INTRODUÇÃO}

O álcool vem sendo indicado como a droga mais ingerida no Brasil. A forma como o álcool é comercializado favorece o seu consumo e isso é considerado uma das principais causas do alcoolismo. O alcoolismo afeta milhões de brasileiros, e é considerado, por órgãos competentes, como um problema de saúde pública e um dos maiores causadores de acidentes de trânsito, homicídios, suicídios e agressões. (BUCHER, 2009).

O consumo excessivo de álcool pode gerar danos hepáticos, as pessoas que fazem uso abusivo do álcool depois de alguns anos podem sofrer com essas complicações. A doença hepática alcoólica é uma doença em que se ligam fatores clínicos, biológicos e psicológicos. (MAHER, 2007).

O principal sítio de metabolização do álcool é o fígado e quando a quantidade consumida é maior que a sua capacidade de metabolização, o órgão começa a sofrer lesões, que pode levar vários anos até começar a se manifestar. (MATTOS, 1997).

Uma parcela de 2 a 10\% do álcool consumido é eliminado pelos rins e pulmões, os 90\% restantes são metabolizados pelo fígado que contém enzimas que fazem a quebra do álcool em outras substâncias. (MINCIS, 2008).

Metabolizado no fígado, o álcool passa por duas reações de oxidação, primeiramente é convertido em acetaldeído pela álcool desidrogenase, depois o acetaldeído é oxidado em acetato pela aldeído desidrogenase. (CHAMPE; HARVEY, 2000).

A álcool desidrogenase é uma enzima induzível, quando aumenta os níveis de álcool no organismo consequentemente ela tem seus níveis aumentados. Essa etapa acontece muito rapidamente nos alcoolistas. Depois disso vem a formação do acetaldeído, que pode ter como sintomas, dores de cabeça, náuseas, desconforto abdominal, entre outros. Quando o fígado tem como primeira opção metabolizar o álcool e outras drogas, começa a deixar de lado suas outras funções. A longo prazo isso implicará numa insuficiência hepática. (CAMPBELL, 2005).

O álcool é retirado do sistema sanguíneo num valor de aproximadamente 15 $\mathrm{mg} / 100 \mathrm{~mL} /$ hora, embora varie de pessoa para pessoa. O consumo exagerado de álcool exige um grande esforço feito pelo fígado, por exemplo, meia garrafa de uísque é equivalente ao metabolismo de $500 \mathrm{~g}$ de aspirina e cerca de 1,2kg de tetraciclina. (PATON, 2005).

O risco de doença hepática alcoólica é determinado não só pela quantidade de álcool consumido, mas também, pelo tempo de consumo. O abuso do álcool vem sido 
considerado uma das principais causas de dano hepático (GANONG, 2006).

Há muitas formas do álcool lesar o fígado, porém nem todos os alcoolistas desenvolvem dano hepático. Os homens apresentam maior tendência a beber mais precocemente e em maiores quantidades que as mulheres e também a manifestar tanto alcoolismo quanto problemas associados ao uso de álcool. Os aspectos genéticos que predispõem ao alcoolismo apontam para influência também dos genes envolvidos com a ação enzimática de metabolização do álcool (GRANT, 2008).

O diagnóstico laboratorial do dano hepático pode ser realizado através do doseamento das enzimas: TGO (transaminase glutâmica oxalacética) e TGP (transaminase glutâmica pirúvica). Estas duas enzimas estão presente nos hepatócitos e toda a vez que as células que contém essas enzimas sofrem alguma lesão elas migram para o sangue; e ainda a GAMA-GT que tem valor aumentado quando há lesão nas vias biliares. Além do doseamento das enzimas, pode ser feito o doseamento da albumina, que quando há algum dano hepático diminui a sua concentração, por ser produzida pelo fígado, e o da ureia, que faz o metabolismo do nitrogênio, e fica diminuída quando há lesão hepática (NASCIMENTO, 2013).

Sendo assim o objetivo deste trabalho foi determinar a ocorrência de dano hepático em alcoolistas em recuperação de um grupo de Alcoólicos Anônimos do município de Ponta Grossa - Pr.

\section{MATERIAL E MÉTODOS}

O projeto foi submetido e aprovado pelo Comitê de Ética da Faculdades Ponta Grossa (Protocolo 1.591.857/2016). Foram coletadas 30 amostras de sangue no Alcoólicos Anônimos Grupo Esperança no mês maio e junho de 2016. A coleta foi realizada pela autora do trabalho durante os encontros, que ocorriam todas as noites a partir das 19h30min.

Foram dosados os mesmos parâmetros em um Grupo Controle com 10 pacientes que foram escolhidos por não apresentarem problemas no fígado ou fizessem uso de algum medicamento que pudesse influenciar. A coleta foi realizada pela autora nos meses de maio e junho de 2016.

Foram analisados os parâmetros bioquímicos TGO (transaminase glutâmica oxalacética), TGP (transaminase glutâmica pirúvica), GAMA-GT e albumina desses pacientes. Para a determinação dos parâmetros bioquímicos, foram coletados aproximadamente $4 \mathrm{~mL}$ de sangue em tubo gel separador e centrifugados a $3400 \mathrm{rpm}$ por 
dez minutos para total separação do soro, as amostras foram processadas no aparelho CS 800 da marca Labtest, utilizando métodos de turbidimetria e colorimetria, seus resultados analisados de acordo com os valores de referência apresentado na bula de cada um dos kits utilizados.

Além disso foi aplicado um questionário antes da coleta, para excluir outros interferentes que pudessem estar causando problemas hepáticos (Apêndice I).

As análises estatísticas foram realizadas utilizando o programa estatístico Statistica versão 10.0. Um valor de $p<0,05$ foi considerado estatisticamente significativo em todas as análises.

\section{RESULTADOS E DISCUSSÃO}

Foram analisados 30 pacientes, todos do sexo masculino, com faixa etária de 24 a 65 anos que frequentam os Alcoólicos Anônimos.

A faixa etária predominante entre o grupo em estudo foi de 30 - 40 anos, representando $40 \%$ da população em estudo, seguida da faixa entre 40 - 50 anos de idade (33,33\%). As faixas etárias de 20 - 30 anos e 60 - 70 anos representaram respectivamente $16,66 \%$ e $6,67 \%$ e a faixa menos prevalente foi de 50 - 60 anos (3,34\%). Não foram observados alcoolistas em recuperação com menos de 20 anos e nem mais de 70 anos (Figura 1).

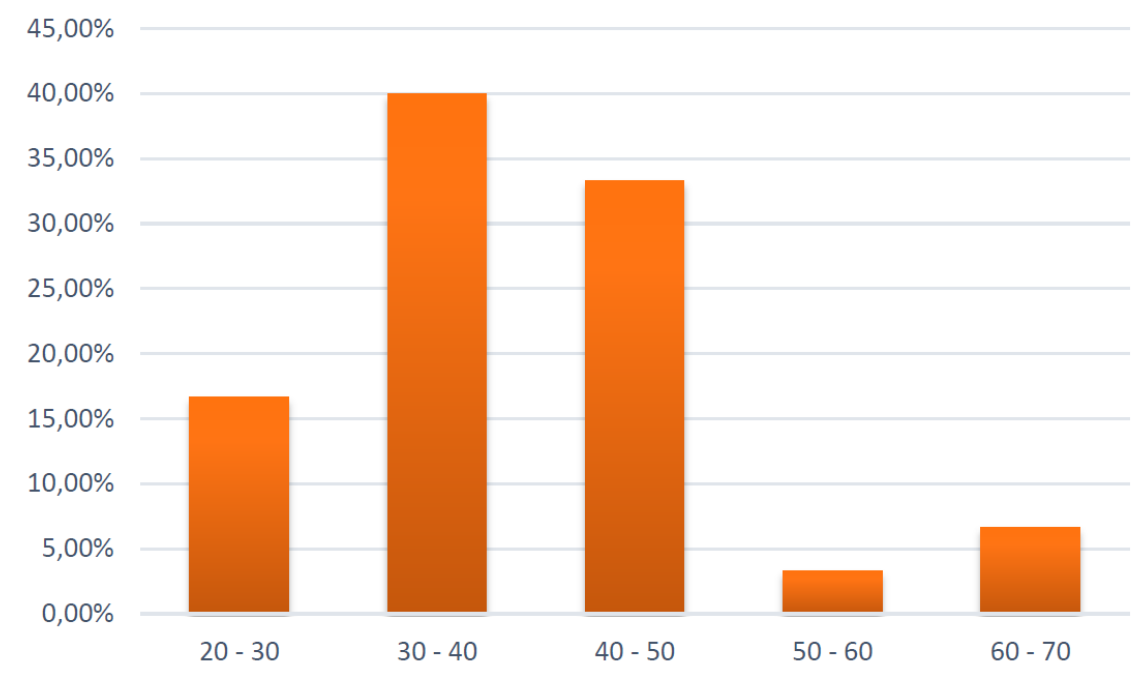

Fonte: O autor (2016)

Figura 1: Faixa etária de alcoolistas em recuperação de um grupo de Alcoólicos Anônimos de Ponta Grossa - Pr. 
Uma pesquisa realizada no estado de São Paulo (cidades com índice populacional maior que 200 mil habitantes) mostrou que cerca de $60 \%$ dos homens que são dependentes do álcool estão na faixa etária de 41 - 53 anos. (GALDURÓZ et al., 2016).

Assim como um estudo quantitativo exploratório realizado no município de Ribeirão Preto, interior do estado de São Paulo, que revelou que 59 pacientes de 119 pesquisados eram dependentes do uso do álcool, destes 16,59\% estavam na faixa de 30 - 49 anos (ANTONIA et al., 2016).

Já Carlini et al. (2007) encontrou que a faixa etária que mais acometeu os dependentes foi a de 18 - 24 anos, logo após a de 25 - 34 anos em uma Unidade de Tratamento de São Paulo, sendo que 77,3\% eram do gênero masculino.

O tempo de consumo de álcool entre os pacientes pesquisados foi de 93,33\% com mais de seis anos de consumo, seguido de 3,34\% com $4-6$ anos de consumo e 3,33\% com 2 - 4 anos de consumo. Não foram observados alcoolistas em recuperação com tempo de consumo inferior a 2 anos (Figura 2).

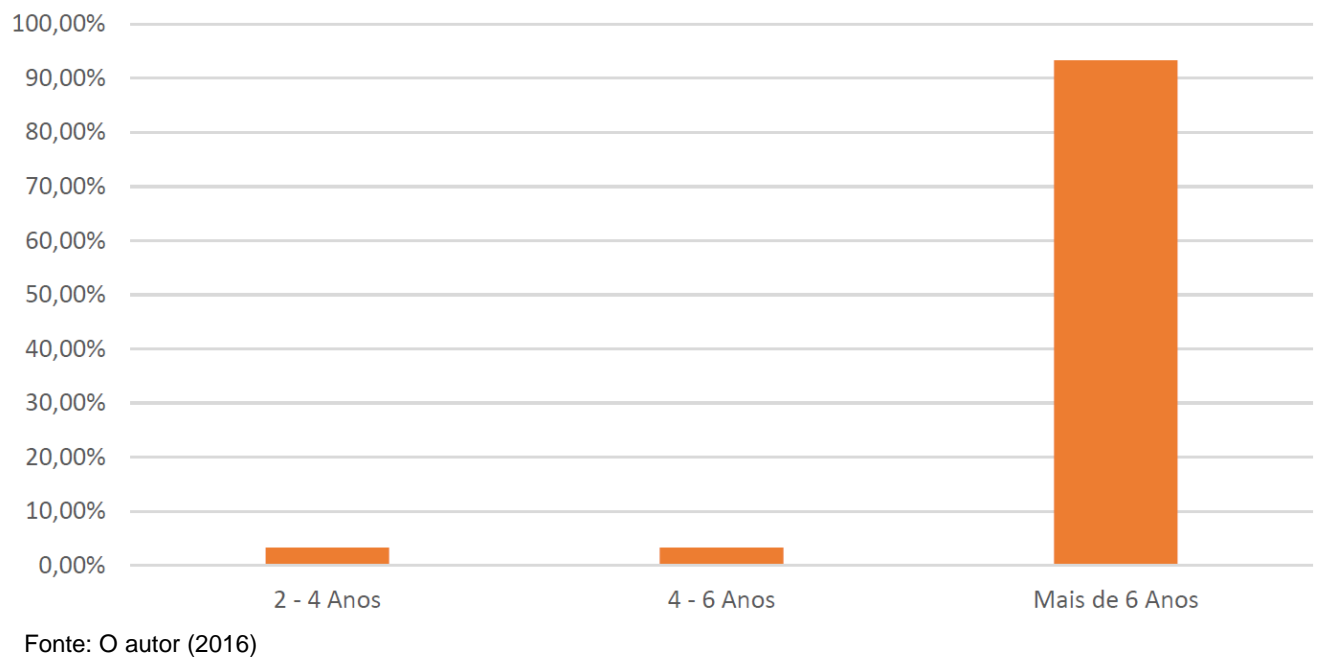

Figura 2: Tempo de consumo de álcool entre alcoolistas em recuperação de um grupo de Alcóolicos Anônimos de Ponta Grossa - Pr.

Segundo Heckman e Silveira (2012), algumas pessoas fazem o metabolismo do álcool mais rapidamente, e algumas também ingerem uma quantidade maior, assim a dependência do álcool aparece cerca de 4 a 6 anos para os menores de 20 anos, e 6 a 8 anos para os adultos.

A cirrose hepática só aparece depois de cerca de 8 - 10 anos de consumo, são formadas várias cicatrizes no fígado que evoluem para um caso de Cirrose Hepática 
Alcóolica (GRANT; DUFOUR; HARFORD, 1988).

Dentre as consequências da dependência do álcool, a cirrose hepática é uma das principais causas de morte, depois de 6 a 9 anos de consumo, a cirrose pode ser uma das doenças que podem acometer os alcoolistas. (PORTUGAL, 2015).

Quanto ao tempo estavam sem utilizar o álcool, 33,67\% estavam de 3 a 6 semanas, 23,33\% de 2 a 4 meses, 33,33\% de 4 a 8 meses e 6,67\% há um ano sem o consumo. Nenhum dos participantes estava a mais de um ano sem consumir álcool (Figura 3).

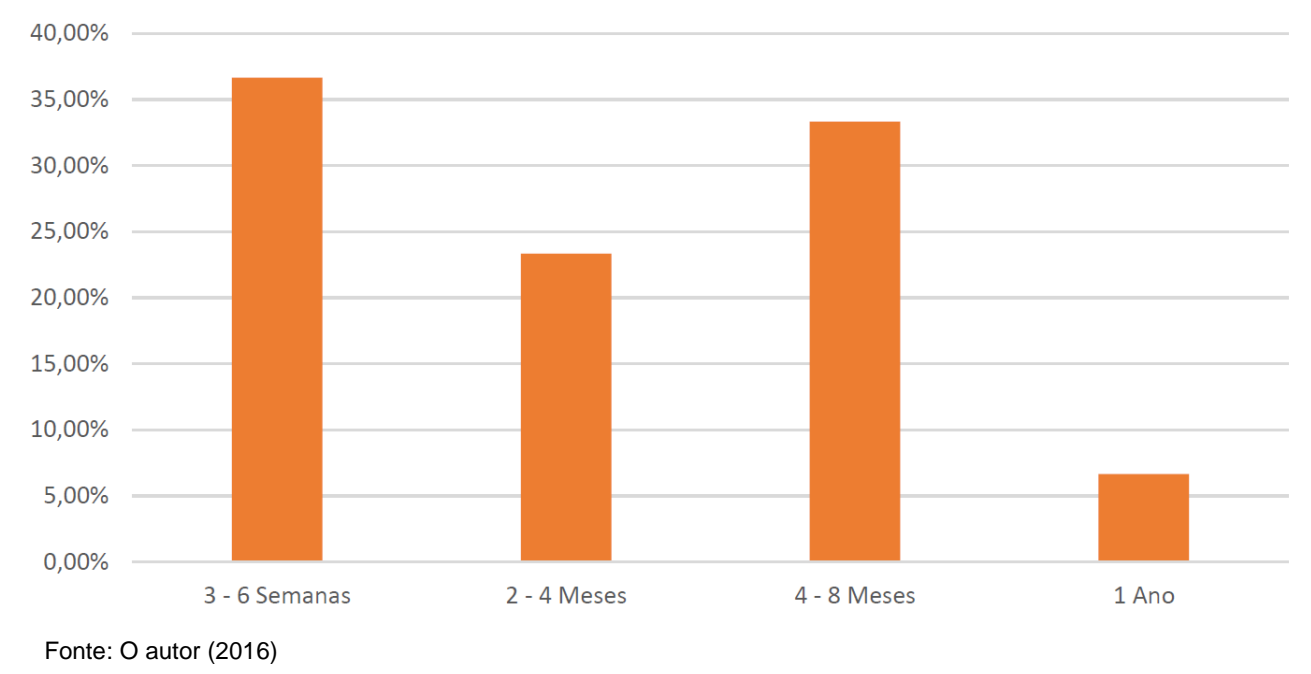

Figura 3: Tempo sem ingerir álcool entre alcoolistas em recuperação de um grupo de Alcóolicos Anônimos de Ponta Grossa - Pr.

O tempo que os especialistas dizem ser necessário para os pacientes conseguirem controlar o seu vício é de três a cinco meses, para que se possa perceber uma mudança na rotina, no humor, nos impulsos e para que o organismo fique limpo e o fígado não sofra mais danos (MATTOS, 2013).

O álcool tem um efeito depressor do Sistema Nervoso Central, uma pessoa que faz consumo exagerado durante vários anos expõe o cérebro continuamente a esse efeito lentificador, se o álcool é retirado de repente o cérebro se comporta com um efeito acelerador, por isso geralmente os alcoolistas conseguem ficar sem consumir somente de 2 a 3 semanas, pois entram em crise de abstinência (LEITE, 2014).

O percentual de familiares com problemas hepáticos dos alcoolistas em recuperação foi de $10 \%$ e o restante (90\%) não apresentaram doenças hepáticas (Figura 4). 


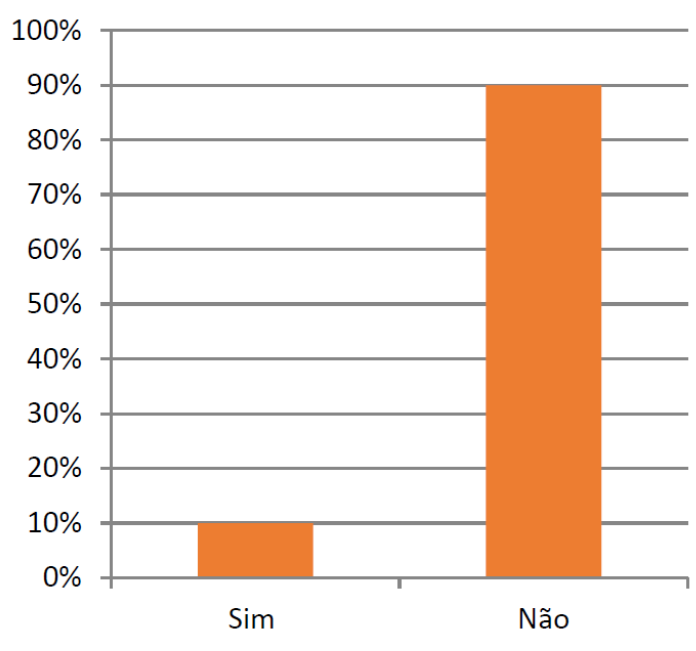

Fonte: O autor (2016)

Figura 4: Familiares com problema Hepático entre alcoolistas em recuperação de um grupo de Alcóolicos Anônimos de Ponta Grossa - Pr.

Um dos fatores de risco para a doença hepática alcóolica é o fator genético familiar, cerca de $75 \%$ dos alcoolistas que desenvolvem danos hepáticos, tem predisposição genética. (MINCIS, 2008).

Fatores genéticos explicam o porque de alguns alcoolistas desenvolverem cirrose hepática e outros não. $O$ tecido cicatrizado que se forma no fígado de pacientes com cirrose é formado por colágeno, assim supõe-se que que diferenças indivíduais nesse gene podem estar associados no desenvolvimento de cirrose. (MAHER, 1997).

Foi levantado ainda se os alcoolistas em recuperação apresentavam algum problema de saúde e apenas $6,66 \%$ responderam que sim (hipertensão arterial em todos os casos). Esses mesmos $6,66 \%$ faziam uso de algum medicamento. $93,34 \%$ não tinham nenhum problema de saúde e não faziam uso de nenhum medicamento (Figura 5).

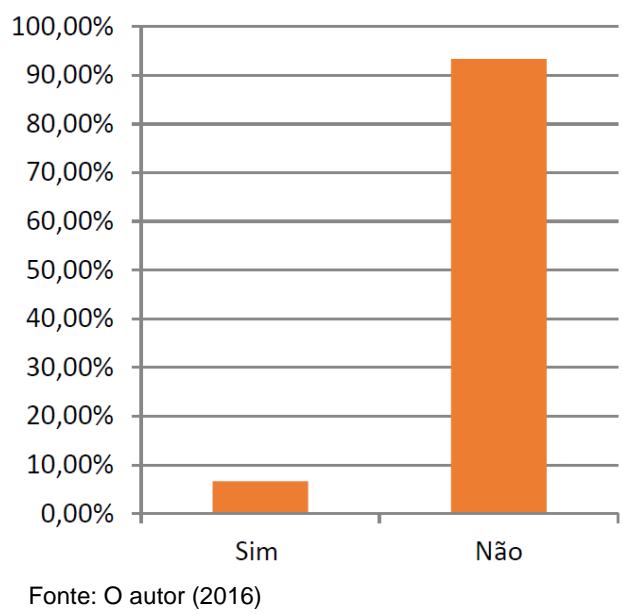

Figura 5: Problemas de Saúde e Uso de Medicamentos entre ex-alcoolistas de um grupo de Alcóolicos Anônimos de Ponta Grossa - Pr. 
O alcoolismo provoca algumas doenças como a hipertensão arterial, a anemia, o aumento da pressão sanguínea, lesões no pâncreas e estômago, entre outras. (LAZO, 2013).

Segundo uma pesquisa realizada na cidade do Rio de Janeiro, cerca de $8 \%$ dos dependentes alcóolicos possuem algum problema de saúde que foi causado pelo uso do álcool e 5\% não faz o tratamento adequado. (HALPERN; LEITE, 2014).

Outra informação verificada foi o uso do cigarro entre os pesquisados, 43,34\% eram tabagistas e 56,66\% não consumiam cigarro (Figura 6).

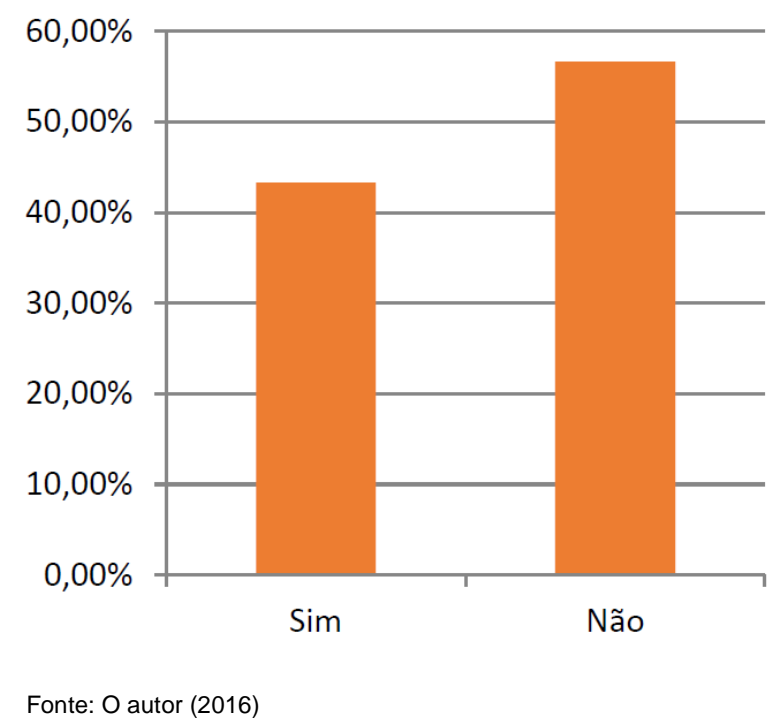

Figura 6: Uso do cigarro entre alcoolistas em recuperação de um grupo de Alcóolicos Anônimos de Ponta Grossa - Pr.

Um estudo feito na Universidade Federal do Rio de Janeiro revela que $31,3 \%$ dos alcoolistas fazem uso do cigarro. (FREIRE; PADILHA; SAUNDERS, 2015).

As pessoas que são dependentes do álcool tem uma tendência maior ao tabagismo, 90\% dos dependentes alcóolicos fumam, sendo que $70 \%$ desses fumam pelo menos um maço por dia. (DROBES, 2002).

Segundo a Organização Mundial de Saúde (OMS) cerca de 2 bilhões de pessoas consomem álcool, desses 76 milhões são alcoolistas e 1,3 bilhões são tabagistas.

Quanto aos parametros bioquimicos, para a transaminase glutâmica oxalacética (TGO) obteve-se uma média de $28,8 \mathrm{U} / \mathrm{L}(+1,93)$ e para o grupo controle de 18,2 U/L (+ 
1,96 ) tendo um valor de referência de até 35,0 U/L (Figura 7). Apesar de ambos os grupos terem os valores dentro dos de referência, os valores encontrados para o grupo em estudo apresentaram diferença estatisticamente significativa $(p<0,05)$ quando comparados ao grupo controle.

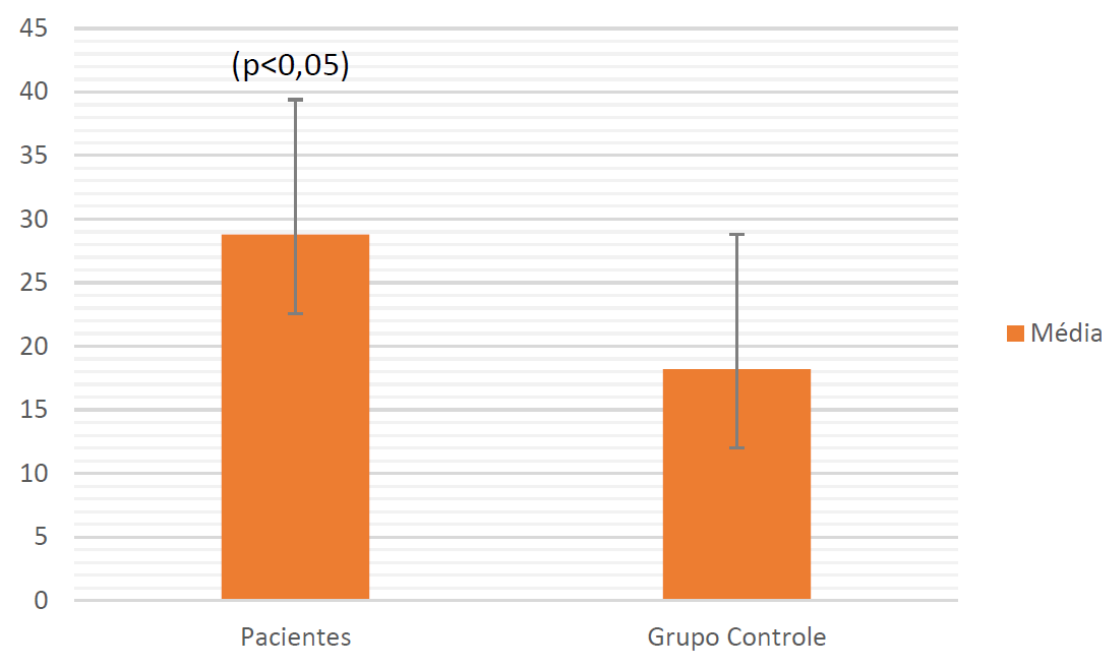

Fonte: O autor (2016)

Figura 7: Transaminase Glutâmica Oxalacética (média e desvio padrão) entre alcoolistas em recuperação de um grupo de Alcóolicos Anônimos de Ponta Grossa - Pr.

Em um estudo feito em Porto Alegre, RS, também foram observados valores normais para o TGO em 10 pacientes (34,4\%) e a média foi de 52,3 U/L. É muito importante que o paciente não tenha feito uso do álcool no dia da coleta para diagnóstico de lesão hepática. (ZAMIN et al., 2002).

Segundo Gonçalves (2009) os alcoolistas, na maioria das vezes tem resultados normais nos testes bioquímicos com AST (TGO) menor que $30 \mathrm{U} / \mathrm{L}$, comparados a quem já tem doença alcóolica que tem uma razão AST/ALT superior a 2.

Quando o TGO tem um resultado menor ou igual a 2 vezes o TGP indica que o paciente tem um diagnóstico de Hepatite Alcóolica e geralmente fica abaixo de $300 \mathrm{U} / \mathrm{L}$ em doenças alcóolicas. (SANTO; MARTINS; GOMES, 2011).

Para a transaminase glutâmica pirúvica (TGP) a média para o grupo pesquisado foi de 44,6 U/L (+ 15,58) e para o grupo controle 23,4 U/L $(+7,48)$ tendo um valor de referência de até $41,0 \mathrm{U} / \mathrm{L}$ (Figura 8). Os resultados não foram significativos $(p>0,05)$ quando comparados 
ao grupo controle.

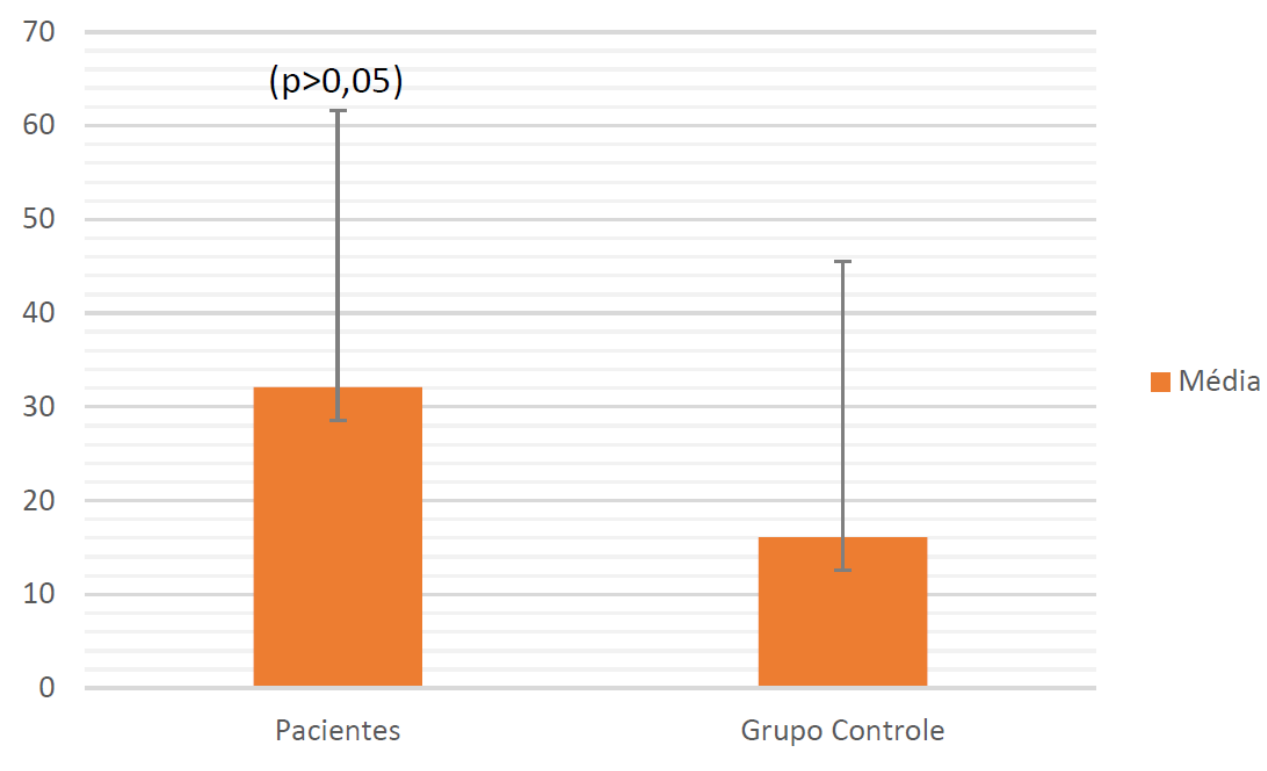

Fonte: O autor (2016)

Figura 8: Transaminase Glutâmica Pirúvica (média e desvio padrão) entre alcoolistas em recuperação de um grupo de Alcóolicos Anônimos de Ponta Grossa - Pr.

A Transaminase Glutâmica Pirúvica (TGP) é considerada um marcador específico de dano hepático. A positividade para o diagnóstico de doença hepática alcóolica é de 96\% quando a relação TGO/TGP é maior que 3. (MINCIS, 2008).

Se houver uma lesão superficial e difusa, na hepatite alcóolica aguda, o TGP é encontrado em maior quantidade do que o TGO, como é uma enzima mais específica de lesão hepática, geralmente em casos de lesões causadas pelo álcool é encontrada em maior quantidade que a TGO. (BARRETO, 2011).

O TGP é encontrado em altas concentrações no citoplasma das células do fígado, quando há lesão, há rompimento celular e liberação de TGP na corrente sanguínea, quando o TGP é maior $300 \mathrm{U} / \mathrm{l}$ pode se levar em consideração doença hepática alcóolica. (BOEMEKE et al., 2015).

A Gama Glutamil Transferase (GAMA-GT) entre o grupo em estudo obteve uma média de atividade de 40,8 U/L $(+6,15)$ e 15,1 U/L $(+2,25)$ para o grupo controle entre um valor de referência de 0,0 a 55,0 U/L (Figura 9). Os valores encontrados para o grupo em estudo apresentaram diferença significativa $(p<0,05)$ quando comparados ao grupo controle. 


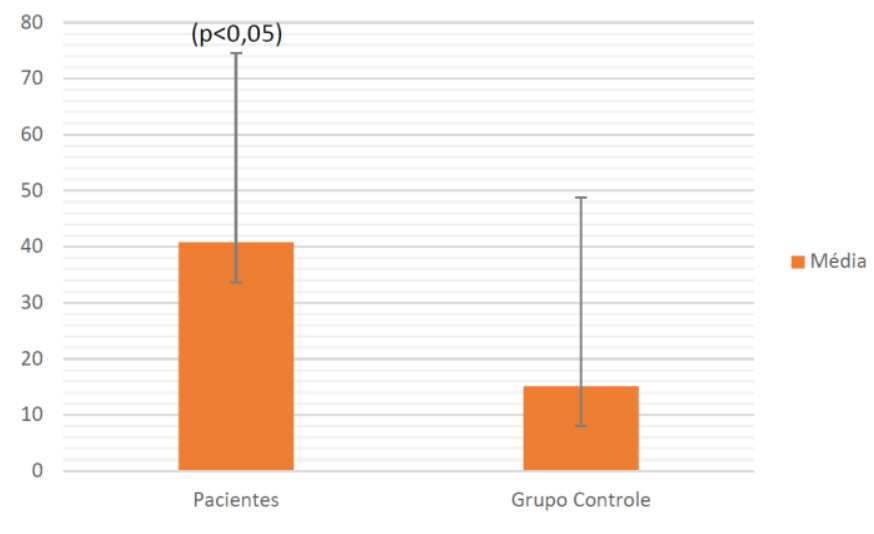

Fonte: O autor (2016).

Figura 9: GAMA-GT (média e desvio padrão) entre alcoolistas em recuperação de um grupo de Alcóolicos Anônimos de Ponta Grossa - Pr.

O GAMA-GT é uma enzima encontrada nos rins, no fígado, no pâncreas, no intestino e na próstata, porém é um marcador muito sensível de doença hepática, pois se encontra alterada em 90\% dos casos de doença hepatobiliar. (JORGE, 2010).

Enquanto a TGO e a TGP são enzimas que avaliam lesão nas células do fígado, o GAMA-GT é uma enzima que se eleva quando há lesão nas vias biliares, geralmente em casos de doença hepática alcóolica é a primeira enzima a se alterar. (GONÇALVES; GONÇALVES; PEREIRA, 2014).

Um estudo feito com 167 consumidores excessivos de álcool, na Universidade de Coimbra, revelou que em $86,7 \%$ dos pacientes o GAMA-GT se encontrou acima do normal, e no grupo controle 19\% estava acima do normal. (ANDRADE et al., 1992).

A Albumina entre os pacientes teve uma média de $4,9 \mathrm{~g} / \mathrm{dL}( \pm 0,09)$ contra média de $4,8 \mathrm{~g} / \mathrm{dL}( \pm 0,11)$ do grupo controle entre um valor de referência de 3,5 a 4,8 g/dL (Figura 10). Os resultados não foram significativos $(p>0,05)$ quando comparados ao grupo controle.

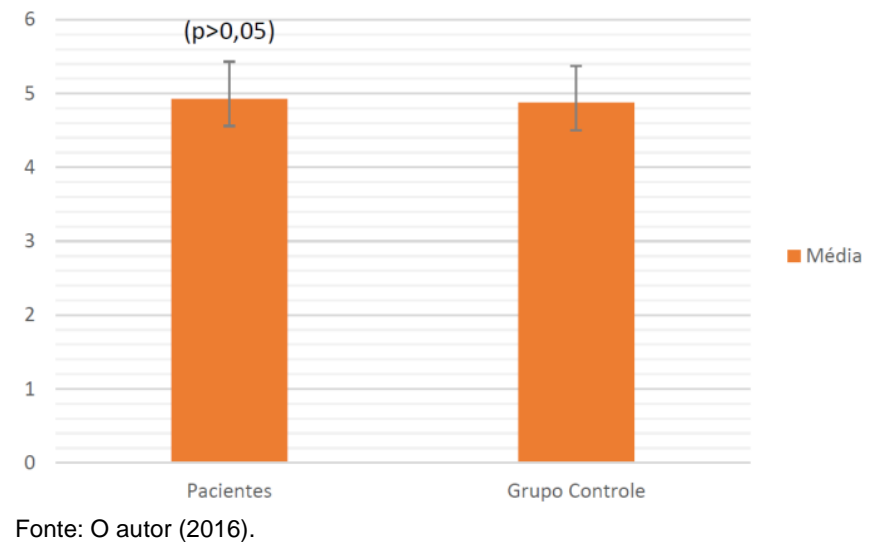

Figura 10: Albumina (média e desvio padrão) entre alcoolistas em recuperação de um grupo de Alcóolicos Anônimos de Ponta Grossa - Pr. 
A albumina é metabolizada exclusivamente no fígado, a diminuição dos seus níveis séricos, assim como a sua produção hepática é agravado quanto maior for a lesão hepática. (MENDES, 2009).

Um estudo feito em Campo Grande, Mato Grosso do Sul com 41 casos de cirrose hepática revelou que $48,4 \%$ dos pacientes tiveram alterações na dosagem de albumina sérica. (UEHARA et al., 2006).

O hepatócito, que é a célula funcional do fígado é o principal produtor de albumina, quando há falência crônica do fígado há hipoalbuminemia. (NASCIMENTO, 2013).

\section{CONCLUSÃO}

Conclui-se que $100 \%$ dos pacientes pesquisados são do gênero masculino, a maioria está na faixa de 30 a 50 anos de idade, cerca de $43,34 \%$ são fumantes e apenas 6,66\% tem algum problema de saúde e faz uso de algum medicamento.

Conclui-se ainda que os parâmetros TGO e GAMA-GT foram estatisticamente significativos apresentando uma elevação quando comparados ao grupo controle, apesar de se encontrarem dentro dos valores de referencia. Os parâmetros TGP e a Albumina não apresentaram diferença estatística.

\section{REFERÊNCIAS}

ANDRADE, C.; ROCHA, M., L.; SOFIA, C.; PRAGANA, M., L.; OLIVEIRA, M., R.; PORTElA, F.; MONTEIRO, G. Gama-GT e Doença Hepática Alcóolica. Acta Media Portuguesa, v. 157, n.5, 1992.

ANTONIA, M.; BARBOSA, S., P.; LUCHESI, L., B.; SANTOS, J., L., F. Síndrome de dependência alcoólica em serviços de emergência. Enferm. glob., v. 15, n. 41, 2016.

Disponível em: http://scielo.isciii.es/scielo.php?script=sci_arttext\&pid=S1695- 6141201600 0100005\&lng=es\&nrm=iso\&tlng=pt. Acesso em 8 jul. 2016.

BARRETO, M., C. Determinação da atividade plasmática das Transaminases TGO e TGP. Cad. de Saúde Pública, v. 8, n. 24, 2011. Disponível em: http://www.barreto.uac.pt/bqm_ 
prat/03ppt_Pesquisar_artigos.pdf. Acesso em 8 jul. 2016.

BOEMEKE, L.; BASSANI, L.; MARRONI, C., A.; GOTTSCHALL, C., B., A. Perfil Lipídico de pacientes cirróticos e sua relação com o desfecho clínico. Arq. Bras. de Cir. Digestiva, v. 28, n. 2, 2015. Disponível em: http://www.scielo.br/scielo.php?script=sci_arttext\&pid=S010 2-67202015000200132\&lng=en\&nrm=iso\&tlng=pt. Acesso em 8 jul. 2016.

BUCHER, R. Drogas e drogadição no Brasil. 1. Ed. Porto Alegre: Artes Médicas, 2009. 72 p.

CAMPBELL M. K. Bioquímica. 3. ed. Porto Alegre: Artmed, 2005. 328 p.

CHAMPE, P. C; HARVEY, R. A. Bioquímica llustrada. 2. ed. Porto Alegre: Artmed, 2000. 554 p.

DROBES, D., J. Concurrent Alcohol and Tobacco Dependence. Alcohol Res. Health, v. 26, n. 2, 2002.

FREIRE, K.; PADILHA, P., C.; SAUNDERS, C. Fatores associados ao uso de álcool na gestação. Rev. Bras. De Ginec. e Obst., v. 31, n. 7, 2015.

GALDURÓZ, J., C., F.; NOTO, A., R.; NAPPO, S., A.; CARLINI, E., A. Uso de Drogas Psicotrópicas no Brasil: pesquisa domiciliar envolvendo as 107 maiores cidades do País. Revista Latino-Americana de Enfermagem, v. 13, n. especial, 2001.

GANONG, W. F. Fisiologia Médica. 22. ed. Rio de Janeiro: Mc Graw Hill, 2006. 607 p.

GONÇALVES, L., I., B. Alcoolismo e Cirrose Hepática. Cad. Saúde Pública, v. 12, n. 8, 2009.

GONÇALVES, P., L.; GONÇALVES, C., S.; PEREIRA, F., E., L. Mortalidade por Cirrose Hepática no Estado do Espírito Santo, Brasil. Cad. de Saúde Pública, v. 30, n. 6, 2014.

GRANT, B. F.; DUFOUR, M. C.; HARFORD, T. C. Epidemiology of alcoholic liver disease. Seminars in Liver Disease. v. 8, n.1 p.12-25, 1988.

GRANT, B., F. National Institute on Alcohol and Alcoholism - NIAAA. Alcohol and the liver, v. 9 , n. $19,2008$. 
HALPERN, E., E.; LEITE, L., C. Etilismo na Jornada Laboral: peculiaridades da vida naval. Saúde e Sociedade, v. 23, n. 1, 2014.

HECKMAN, W.; SILVEIRA, C., M. Dependência do Álcool: aspectos clínicos e diagnóstico. Cad. de Saúde Pública, v. 17, n. 3, 2012.

JORGE, S., G. Exames Laboratoriais Hepáticos. Cad. de Saúde Pública, v. 32, n. 8, 2010.

JORGE, S., G. Relatório Brasileiro sobre Drogas. Ciência e Saúde Pública, v. 19, n. 1, 2014.

LAZO, R., B. Dieta para recuperação de Alcoolistas. Cad. de Saúde Pública, v. 21, n. 5, 2013.

LEITE, M., C., P. Síndrome da Abstinência Alcóolica. Rev. Bras. de Enfermagem, v. 39, n. 12, 2014.

MAHER, T. J. Exploring alcohol effects on Liver Function. Alcohol Health and Research World. v. 21, n. 1, 1997.

MOTA, L. A. . A Dádiva da Sobriedade: a ajuda mútua nos grupos de Alcoólicos Anônimos. 1ª ed. São Paulo: Paulus, 2004. 199p .

MENDES, M., R. Carga de doença no Brasil: um olhar sobre o álcool e a cirrose não viral. Ciência e Saúde Coletiva, v. 20, n. 2, 2009.

MINCIS, M. Doença Hepática induzida por drogas. 4 ed. São Paulo: Casa Lemos Editorial, 2008. p. 883-891.

NASCIMENTO, A., C. Patologia do Fígado: Anatomia e Fisiologia, Cad. de Saúde Pública, v. 19, n. 9, 2013. Disponível em: http://www.ufjf.br/deptopatologia/files/2011/08/Aula10.06.2013-Patologia-hep\%C3\%A1tica.pdf. Acesso em 8 jul. 2016.

PATON, A. ABC of Alcohol. 4 ed. Oxford: Blackwell, 2005. 55 p.

PORTUGAL, F., B. Doença Hepática: um olhar sobre o álcool. Cienc. e Saúde Coletiva, v. 13, n. 4, 2015. Disponível em: http://www.scielo.br/scielo.php?script=sci_arttext\&pid=S1413- 
81232015000200491 \&lang=pt. Acesso em 8 jul. 2016.

SANTO, J., E.; MARTINS, L.; GOMES, M., F. Algoritmo de investigação das alterações das provas hepáticas. Cad. de Saúde Pública, v. 24, n. 3, 2011. Disponível em: http://www. updatemedicina.com/arquivo/2011/updatemedicina2011-algoritmo-investigacao-provas -hepaticas.pdf. Acesso em 8 jul 2016.

UEHARA, P., M.; CUNHA, R., V.; PEREIRA, G., R., O., L.; OLIVEIRA, P., A. Envolvimento hepático em pacientes Alcoolistas. Revista da Sociedade Brasileira de Medicina, v. 39, n. 6, 2006.

ZAMIN, I.; MATTOS, A., A.; PERIN, C.; RAMOS, G., Z. A importância do índice AST/ALT no diagnóstico da esteatohepatite não alcóolica. Arq. Gastroenterol, v. 39, n. 1, 2002. Disponível em: http://www.scielo.br/pdf/ag/v39n1/a05v39n1. Acesso em 8 jul. 2016. 